\title{
Article
}

\section{Electroanalytical properties of chlorophenol red at disposable carbon electrodes: Implications for Escherichia coli detection}

Casimero, Charnete, Bigham, Teri, McGlynn, Ruairi J., Dooley, James S.G., Ternan, Nigel G., Snelling, William J., Critchley, Megan, Zinkel, Cameron Luke, Smith, Robert B, Sabogal-Paz, Lyda P. and Davis, James

Available at http://clok.uclan.ac.uk/29045/

Casimero, Charnete, Bigham, Teri, McGlynn, Ruairi J., Dooley, James S.G., Ternan, Nigel G., Snelling, William J., Critchley, Megan, Zinkel, Cameron Luke, Smith, Robert B ORCID: 0000-0002-2829-5360 et al (2019) Electroanalytical properties of chlorophenol red at disposable carbon electrodes: Implications for Escherichia coli detection. Bioelectrochemistry, 130 (107321). ISSN 15675394

It is advisable to refer to the publisher's version if you intend to cite from the work. http://dx.doi.org/10.1016/j.bioelechem.2019.06.006

For more information about UCLan's research in this area go to

http://www.uclan.ac.uk/researchgroups/ and search for <name of research Group>.

For information about Research generally at UCLan please go to http://www.uclan.ac.uk/research/

All outputs in CLoK are protected by Intellectual Property Rights law, including Copyright law. Copyright, IPR and Moral Rights for the works on this site are retained by the individual authors and/or other copyright owners. Terms and conditions for use of this material are defined in the policies page. 


\section{Accepted Manuscript}

Electroanalytical properties of chlorophenol red at disposable

carbon electrodes: Implications for Escherichia coli detection

Charnete Casimero, Teri Bigham, Ruairi J. McGlynn, James S.G. Dooley, Nigel G. Ternan, William J. Snelling, Megan E. Critchley, Cameron L. Zinkel, Robert B. Smith, Lyda P. Sabogal-Paz, James Davis

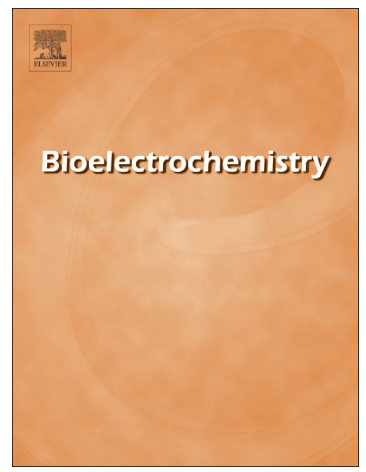

PII: S1567-5394(19)30344-5

DOI: https://doi.org/10.1016/j.bioelechem.2019.06.006

Reference: BIOJEC 7321

To appear in:

\section{Bioelectrochemistry}

Received date:

24 May 2019

Revised date:

19 June 2019

Accepted date:

19 June 2019

Please cite this article as: C. Casimero, T. Bigham, R.J. McGlynn, et al., Electroanalytical properties of chlorophenol red at disposable carbon electrodes: Implications for Escherichia coli detection, Bioelectrochemistry, https://doi.org/10.1016/ j.bioelechem.2019.06.006

This is a PDF file of an unedited manuscript that has been accepted for publication. As a service to our customers we are providing this early version of the manuscript. The manuscript will undergo copyediting, typesetting, and review of the resulting proof before it is published in its final form. Please note that during the production process errors may be discovered which could affect the content, and all legal disclaimers that apply to the journal pertain. 


\section{Electroanalytical Properties of Chlorophenol Red at Disposable Carbon}

\section{Electrodes: Implications for Escherichia coli Detection}

Charnete Casimero ${ }^{1}$, Teri Bigham ${ }^{1,2}$, Ruairi J. McGlynn ${ }^{1}$, James S.G. Dooley ${ }^{2}$, Nigel G. Ternan ${ }^{2}$, William J. Snelling ${ }^{2}$, Megan E. Critchley ${ }^{3}$, Cameron L. Zinkel ${ }^{3}$, Robert B. Smith ${ }^{3}$, Lyda P. Sabogal-Paz ${ }^{4}$ and James Davis ${ }^{1, *}$ james.davis@ulster.ac.uk

${ }^{1}$ Nanotechnology and Integrated Bioengineering Centre, School of Engineering, Ulster University, Jordanstown, Northern Ireland, BT37 OQB

${ }^{2}$ Microbiology, Nutrition Innovation Centre for food and Health (NICHE), School of Biomedical Sciences, Ulster University, Coleraine, Northern Ireland, BT52 1SA

${ }^{3}$ Chemistry, School of Physical Sciences and Computing, University of Central Lancashire, Preston, PR1 2HE

${ }^{4}$ Department of Hydraulics and Sanitation, Sao Carlos School of Engineering, University of Sao Paulo, Trabalhador SaoCarlense Avenue, 400, Sao Paulo, 13566-590, Brazil

*Corresponding author. 


\section{Abstract}

The use of coliforms and Escherichia coli as indicator species for assessing the quality of water is well established and a large variety of methods based on $\beta$-galactosidase (B-GAL) activity, inherent to the microbes within this classification, have arisen to enable their detection and enumeration. Chlorophenol red (CPR) is widely used as a chromogenic label, but its capacity for translation to electroanalytical devices has yet to be fully explored. The CPR moiety is capable of undergoing oxidation at carbon substrates $(+0.7 \mathrm{~V})$ giving rise to a variety of phenolic intermediates. Electrochemical, XPS and enzymatic techniques were employed to characterise the underpinning chemistry and the intermediate identified as a 1,2-quinone derivative in which the chlorine substituent is retained. The latter was found to accumulate at the electrode and, in contrast to the parent CPR, was found to be detected at a significantly less positive potential $(+0.3 \mathrm{~V})$. Bacterial hydrolysis of a CPR labelled substrate was demonstrated with the 1,2-quinone oxidation product found to accumulate at the electrode and detected using square wave voltammetry. Proof of concept for the efficacy of the alternative electrode pathway was established through the detection of E.coli after an incubation time of $2.5 \mathrm{~h}$ with no interference from the labelled substrates.

Keywords: Galactosidase; Chlorophenol Red; Coliform; Water Quality; Global Health 


\subsection{Introduction}

Electroanalytical techniques which target the detection of molecular biomarkers have a long history and there have been many technological advances in past decades [1-6]. It is only recently however that attention has shifted from small molecular targets to larger moieties such as bacteria [7-10]. The $\beta$-galactosidase (B-GAL) enzyme common to most coliforms offers a versatile route through which small molecule detection can be still be harnessed to detect the presence of these larger targets. The B-GAL enzyme, which is encoded by the lacZ gene, catalyzes the hydrolysis of $\beta$ galactosides (such as lactose) into monosaccharides (such as glucose and galactose) and has been the subject of extensive investigations with a history dating back to the mid 1900's. Monitoring the enzyme activity has enabled insights into the genetic regulation of enteric bacteria $[11,12]$ and has since found use in a host of applications [13]. The prevalence of B-GAL in coliforms and E. coli, however, has seen the enzyme's significance move from fundamental science to the development of low cost field diagnostics for water quality measurements in low and middle income countries. Coliforms are used as the principal indicator organisms that highlight faecal contamination of water sources and, at present, B-GAL forms the foundation of a diverse range of assay systems [14-17]. Bigham et al. (2019) recently demonstrated the potential of voltammetric approach with a carbon fibre system to quantify $\mathrm{pH}$ for microbial coliform water quality assessment [18]. Irrespective of the assay format, the underpinning methodology relies upon the ability of the enzyme to hydrolyse labelled galactopyranoside substrates yielding a colorimetric, fluorescent, luminescent or electrochemical marker [19]. A large variety of molecular species have been used as markers to enable quantification but chlorophenol red (CPR) has emerged as a more convenient and highly sensitive substrate from both spectroscopic [13] and electrochemical perspective [20] as indicated in Schematic 1.

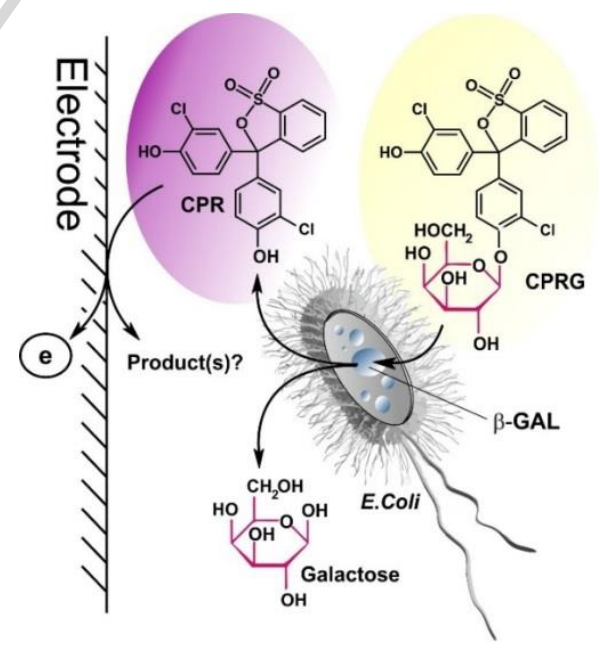

Schematic 1. Spectroscopic or electrochemical detection of Escherichia.coli through the $\beta$-galactosidase ( $\beta$ GAL) mediated hydrolysis of chlorophenol red - galactopyranosidase (CPRG). 
Electrochemically, CPR has been shown to be capable of direct oxidation at carbon electrodes and Wutor and colleagues (2007) demonstrated detection limits as low as 1 colonyforming unit (CFU) / $100 \mathrm{~mL}$ [20]. This is widely regarded as the threshold for microbial drinking water quality required by the Sustainable Developments Goals (SDGs), which were ratified by the United Nations [21]. Inspection of the CPR molecular structure (highlighted in Schematic 1) reveals two discrete 2-chlorophenol functionalities, the oxidation of which are attributed to the electrochemical peak process observed by Wutor and colleagues. The products of the oxidation process however were unascribed, but it is inevitable that a range of intermediates could arise, and some tentative pathways are highlighted in Fig. 1.

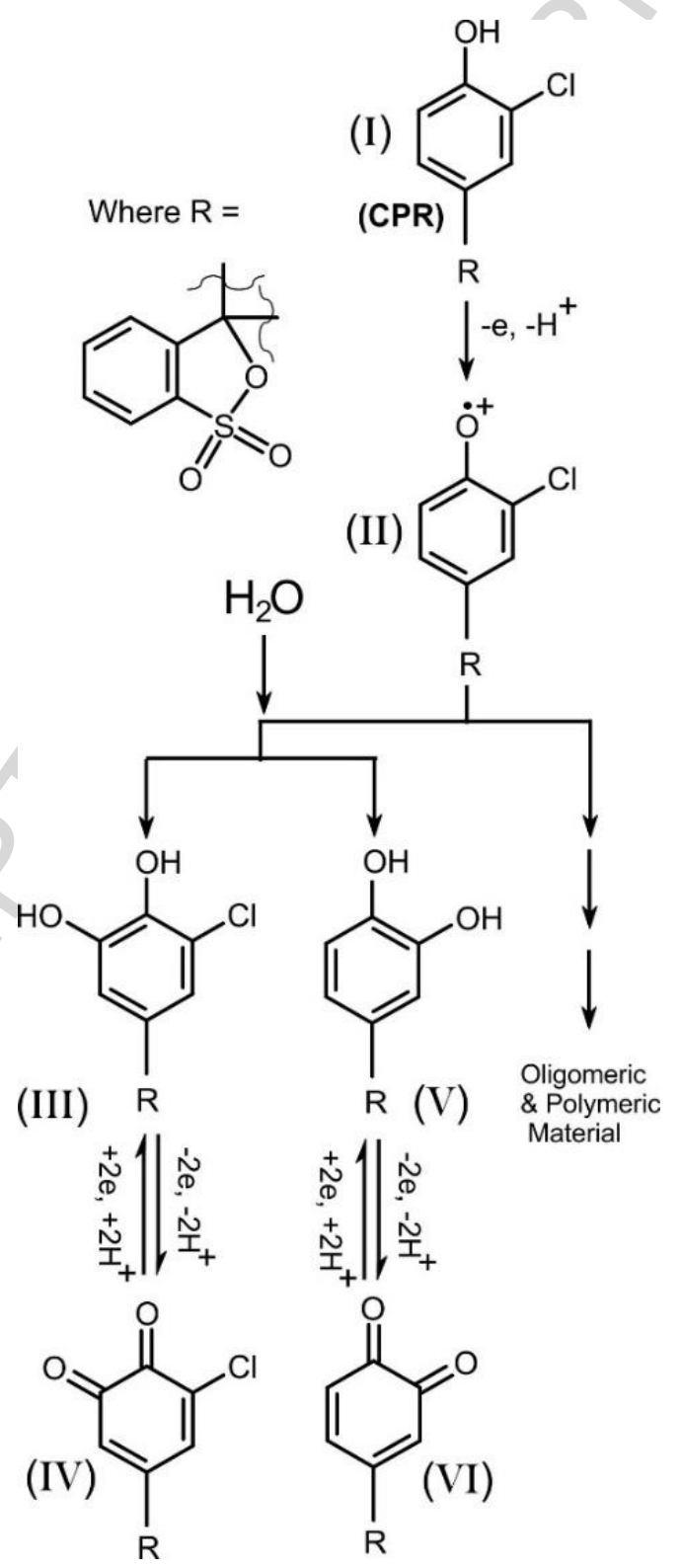

Fig. 1. Possible reaction pathways following the oxidation of chlorophenol red (CPR). 
For the purposes of mechanistic considerations, the CPR molecule could be simplified to a core consisting of two 2-chlorophenol (2CP) groups with the remainder of the molecule being a relatively inert spectator. While there is no mechanistic information on the oxidation of CPR in the literature, there is an abundance of studies on substituted phenols [22-27]. As indicated in Fig. 1, electrochemical oxidation would be expected to lead to the generation of the radical cation $(\mathbf{I} \rightarrow \mathbf{I I})$ and therein to a spectrum of products (II $\rightarrow$ VI). In simple systems with low steric hindrance, this tends to result in coupling to form oligomeric and polymeric species directly at the electrode surface. While similar reactions are inevitable in the oxidation of CPR, the molecular bulk could be a limiting factor allowing competing process to prevail. The CPR structure, by virtue of the blocked 4-position and the 2-chloro substituent, is sterically less likely to form polymeric films upon oxidation, however, the vacant 5-position would be susceptible to attack leading to oligomeric CPR-like aggregations or the production of discrete 1,2-dihydroxy species (III and V). Given that the potential required to oxidise these intermediates is less than that required to oxidise the parent CPR, it could be anticipated that their conversion to the corresponding 1,2-quinone (III $\rightarrow$ IV, V $\rightarrow$ VI) should be immediate upon the imposition of a large positive potential.

Electrochemical signatures pertaining to the intermediates were not reported by Wutor et al., instead their focus was solely on the direct oxidation of the phenol (I $\rightarrow$ II) [20]. As such, a number of questions remain in terms of the possible pathways highlighted in Fig. 1. The oxidation of CPR was observed at $+0.72 \mathrm{~V}$ which can be problematic in complex media where the oxidation of other components (i.e. humic substances) may lead to ambiguities in ascribing the peak currents and could give rise to false positives. In contrast to the direct oxidation of CPR, the electrogenerated 1,2dihydroxy intermediates could be expected to have redox peak processes at much lower potentials. Exploiting their redox signature as the analytical signal for B-GAL activity could potentially avoid interference issues from other species present in the sample. From a more fundamental perspective, there are two competing pathways in Fig. 1 where the chloro substituent is either retained throughout the process or is lost through nucleophilic attack during the initial oxidation. As yet, no investigations into the nature of the electrode products from CPR have been reported. The present study has attempted to counter this issue, but also examine the possibility of exploiting the electrogenerated dihydroxy products as a viable diagnostic tool for detecting B-GAL activity and hence the presence of coliforms.

\subsection{Experimental Details}

Materials and Instrumentation: All chemicals were obtained from Sigma-Aldrich (Gillingham, UK), were of the highest grade available and were used without further purification. Toray Carbon Fibre 
Paper (TGP-H-30) was purchased from E-TEK (USA) and used as received. Electrochemical analysis was carried out using an Anapot potentiostat (Zimmer \& Peacock, Royston UK) with a standard three-electrode configuration with either a glassy carbon ( $3 \mathrm{~mm}$ diameter) or Toray carbon fibre mat $(2.5 \times 2.5 \mathrm{~mm})$ as the working electrode. Platinum wire served as the counter electrode and a conventional silver/silver chloride ( $3 \mathrm{M} \mathrm{KCl}$, BAS Technicol UK) half-cell reference electrode unless otherwise specified. All measurements were conducted at $22^{\circ} \mathrm{C} \pm 2{ }^{\circ} \mathrm{C}$. Carbon fibre electrodes were sealed within a polyester laminate as described previously [28] and pre-anodised in $0.1 \mathrm{M} \mathrm{NaOH}(+2$ $\mathrm{V}, 5$ mins) [29]. Electrochemical measurements were conducted in Britton-Robinson (BR) buffer (acetic, boric and phosphoric acids - each with a concentration of $0.4 \mathrm{M}$ and adjusted to the appropriate $\mathrm{pH}$ through the addition of concentrated sodium hydroxide) unless otherwise specified. While the $\mathrm{pH}$ of treated water can range from $\mathrm{pH} 6$ to $\mathrm{pH}$ 9, the electrochemical investigations were conducted at $\mathrm{pH} 7$ throughout to facilitate comparison of electrode responses. The influence of $\mathrm{pH}$ on the peak responses was however assessed and summarised in the following discussion.

NMR spectra were recorded on a Bruker Avance-III $300 \mathrm{MHz}$ spectrometer at ambient temperature. Chemical shifts are reported in ppm relative to residual protic solvent $\left({ }^{1} \mathrm{H}\right.$ NMR $\mathrm{d}_{6}$-DMSO, $2.500 \mathrm{ppm}$; ${ }^{13} \mathrm{C} N M R d_{6}$-DMSO, $\left.39.520 \mathrm{ppm}\right)$. The preparation of 2-chloronaphthoquinone was based on a method by Neufeind et al.(2011) [30] and is detailed in the Electronic Supporting Information (ESI) file along with the procedures followed and spectra obtained from the NMR investigations.

A Kratos Axis Ultra DLD Spectrometer was used to quantify surface composition and acquire X-ray photoelectron spectroscopy (XPS) spectra. Spectra were analysed using monochromated Al Ka Xrays ( $h v=1486.6$ electron volts $(\mathrm{eV})$ ) with typical operating parameters of $15 \mathrm{kV}$ and $10 \mathrm{~mA}(150 \mathrm{~W})$. During analysis, a hybrid lens mode was used (electrostatic and magnetic) with a $300 \mu \mathrm{m} \times 700 \mu \mathrm{m}$ analysis area and a take-off angle (TOA) of $90^{\circ}$ with respect to the sample surface. Wide energy survey scans (WESS) were collected across a range of -5 to $1200 \mathrm{eV}$ binding energy (BE), with a pass energy of $160 \mathrm{eV}$ and step size of $1 \mathrm{eV}$. High-resolution spectra were collected with a pass energy of $20 \mathrm{eV}$ with a $0.05 \mathrm{eV}$ step size, a scan width of $25 \mathrm{eV}$, a dwell time of 150 milliseconds and at least 3 sweeps to reduce the signal noise. A Kratos charge neutraliser system with a filament current between 1.8-1.95 $\mathrm{A}$ and a charge balance of 3.3-3.6 $\mathrm{V}$ and a filament bias of $1.3 \mathrm{~V}$ was used for all samples. Charging effects on the BE positions were adjusted by setting the lowest BE for the $\mathrm{C} 1 \mathrm{~s}$ spectral envelope to $284.8 \mathrm{eV}$, which is commonly accepted as adventitious carbon surface contamination. Three measurements were analysed per sample, with a Shirley background subtracted from each XPS spectra. The peak areas of the most intense spectral lines for each 
elemental species were used to determine the percentage atomic concentration. Peak fitting of high-resolution spectra was carried out using Casa XPS software.

Bacterial Culture: Escherichia coli (K12, CETC 4624 (NCTC 12486)) was grown from an existing stock (previously stored at $-80^{\circ} \mathrm{C}, 25 \%$ glycerol) by streaking onto a Tryptic Soy Broth (TSB) agar plate containing tryptone $(17 \mathrm{~g} / \mathrm{L})$, soy extract $(3 \mathrm{~g} / \mathrm{L}), \mathrm{NaCl}(5 \mathrm{~g} / \mathrm{L}), \mathrm{K}_{2} \mathrm{HPO}_{4}(2.5 \mathrm{~g} / \mathrm{L})$, glucose $(2.5 \mathrm{~g} / \mathrm{L})$ and $\operatorname{agar}(15 \mathrm{~g} / \mathrm{L})$. A single colony was transferred from the stock plate into $10 \mathrm{~mL}$ of LB broth. The latter was supplemented with $500 \mu \mathrm{M}$ of isopropyl- $\beta$-d-thiogalactopyranoside (IPTG) in accordance with previous reports [31,32] and the resulting mixture added to a $50 \mathrm{~mL}$ falcon tube and incubated at $37^{\circ} \mathrm{C}$ for $18 \mathrm{~h}$ at $150 \mathrm{rpm}$. Overnight cultures were sub-cultured and grown to an $\mathrm{OD}_{600}$ of 0.4 before undergoing a 2 fold serial dilution.

Electrochemical Assay: Lysozyme $(10 \mathrm{mg} / \mathrm{mL})$ was dissolved within Tris buffer, adjusted to a $\mathrm{pH}$ of 8 and added at a $1 \mathrm{mg} / \mathrm{mL}$ concentration to each dilution [33]. This was incubated at room temperature for 20 minutes and then pelleted and the supernatant removed. The pellet was resuspended in Minimal Media (pH 7) consisting of $\mathrm{Na}_{2} \mathrm{HPO}_{4}(25.6 \mathrm{~g} / \mathrm{L}), \mathrm{NaH}_{2} \mathrm{PO}_{4}(5.28 \mathrm{~g} / \mathrm{L}), \mathrm{KCl}(1$ $\mathrm{g} / \mathrm{L}), \mathrm{NH}_{4} \mathrm{Cl}(2 \mathrm{~g} / \mathrm{L}), \mathrm{MgCl}_{2}(0.19 \mathrm{~g} / \mathrm{L})$ and $\mathrm{CaCl}_{2}(0.011 \mathrm{~g} / \mathrm{L})$. Chlorophenol red galactopyranoside (6 $\mathrm{mg} / \mathrm{mL}$ ) was then added and the mixture incubated at $37^{\circ} \mathrm{C}$ over a period of 24 hours. Voltammetric readings were taken at $2.5 \mathrm{~h}$ and $24 \mathrm{~h}$. Electrochemical investigations within the resulting E.coli cultures were conducted through placing the three electrodes (carbon fibre working, $3 \mathrm{M} \mathrm{Ag} / \mathrm{AgCl}$ reference and $\mathrm{Pt}$ counter) within the bacterial culture. Square wave voltammograms $(-0.2 \mathrm{~V}$ to +1.2 V, Step $=2 \mathrm{mV}$, Pulse $=20 \mathrm{mV}$, Frequency $25 \mathrm{~Hz}$ ) were scanned.

\subsection{Results and Discussion}

Cyclic voltammograms detailing the response of an anodised carbon fibre electrode towards $100 \mu \mathrm{M}$ CPR in pH 7 Britton-Robinson (BR) buffer are shown in Fig. 2A. A broad oxidation process $(+0.6 \mathrm{~V})$ is seen on the first scan with the successive decrease in the peak magnitude characteristic of phenol oxidation. The oxidation peak is slightly less positive than that observed by Wutor et al.(2007) and could be attributed to the increased edge plane/interfacial oxygen functional group population associated with anodised carbon fibre [29]. The initial oxidation is irreversible and can be attributed to the generation of the radical cation which is then expected to undergo the various structural transformations as indicated in Fig. 1. Rather than being characteristic of a single electrode process, the breadth and multicomponent structure of the "peak" highlights a multitude 
of secondary processes attributed to the consequent oxidation of reaction by-products. Importantly, a series of new electrode processes are observed on the second scan covering the range: $+0.1 \mathrm{~V}$ to $+0.4 \mathrm{~V}$ and suggests multiple overlapping peak processes. It is important to note that restricting the scan range on the first scan to $+0.5 \mathrm{~V}$ - a potential limit insufficient to induce CPR oxidation - does not lead to the appearance of any secondary redox peak processes. Voltammograms were also recorded in BR buffers covering the range $\mathrm{pH} 6$ to $\mathrm{pH} 9$ and it was observed that the secondary peak process exhibited a shift in peak position of $57 \mathrm{mV} / \mathrm{pH}$ consistent with a 2 proton / 2 electron transition.

As the magnitude of the peak process at $+0.3 \mathrm{~V}$ was found to increase with additional scanning, irrespective of any time delay between scans, it was hypothesised that the products were adsorbed onto the electrode surface and this was tested through removing the electrode, rinsing and placing in fresh $\mathrm{pH} 7 \mathrm{BR}$ buffer devoid of any solution CPR. The resulting voltammograms are highlighted in the Inset in Fig. 2A, where it is clear that the electro-oxidation product is retained and exhibited near-reversible behaviour which was found to be relatively stable with only a $9 \%$ diminution in the peak current after 20 voltammetric cycles. The response to scan rate was also investigated (Fig. 2B and 2C) with the linearity of the peak current vs scan rate being consistent with a surface-confined species. Surface coverage $\left(\Gamma_{c}\right)$ after 8 scans was estimated from:

$I_{P}=\frac{\mathrm{n}^{2} \mathrm{~F}^{2} \mathrm{~A} \Gamma_{\mathrm{c}}}{4 \mathrm{RT}} v$

where $I_{p}$ is the peak height, $v$ is the sweep rate, A is the effective surface area $\left(0.0625 \mathrm{~cm}^{2}\right)$ of the carbon fibre electrode and the other symbols have their usual meaning. From the slope of cathodic peak currents vs. scan rate, the calculated surface concentration of the CPR quinone compound was found to be $2.49 \times 10^{-5} \mathrm{~mol} \mathrm{~cm}^{-2}$. 

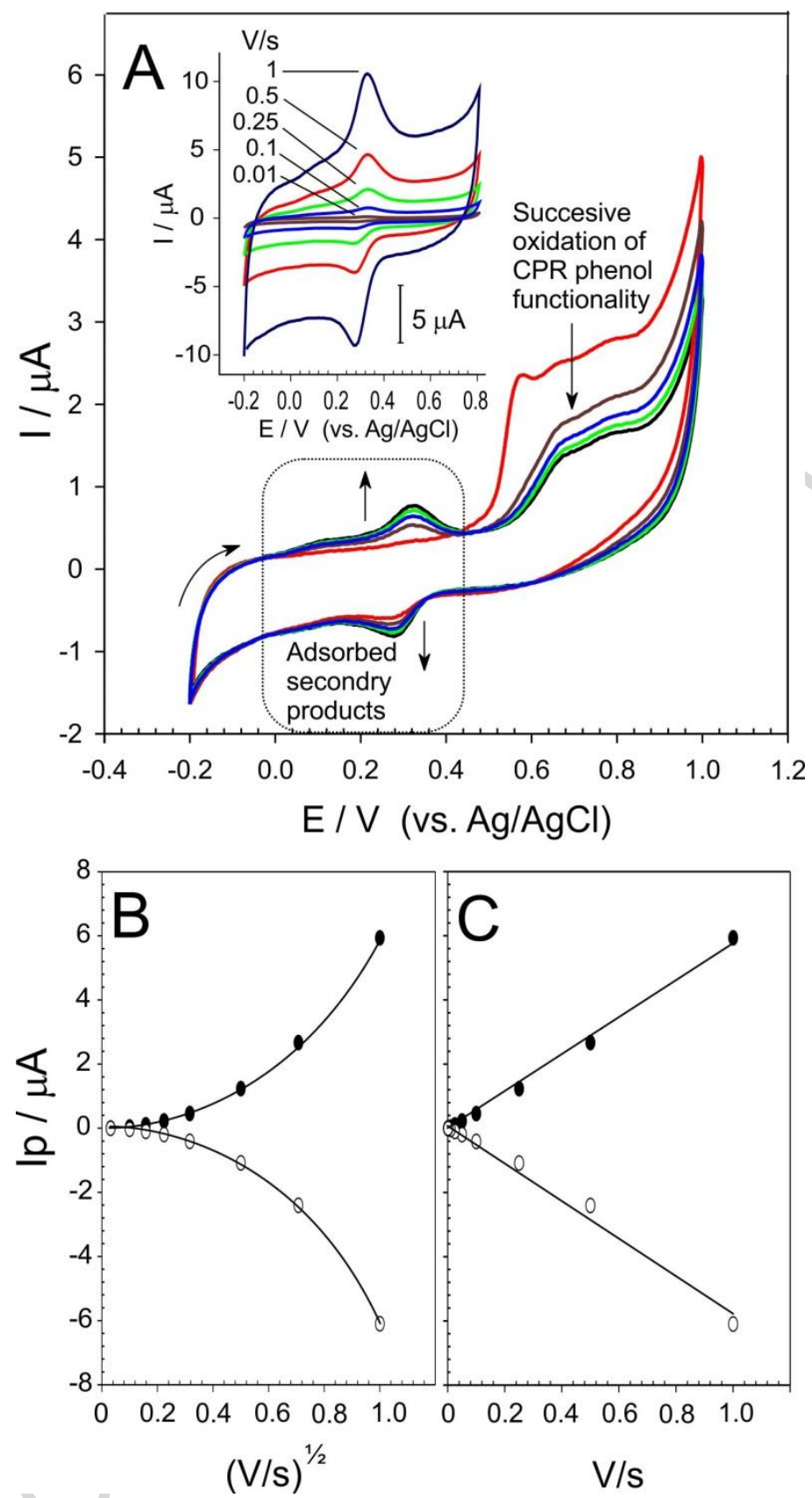

Fig. 2. A) Cyclic voltammograms detailing the oxidation of $100 \mu \mathrm{M}$ chlorophenol red (CPR) at a carbon fibre electrode in $\mathrm{pH} 7$ Britton-Robinson buffer (Scan rate: $50 \mathrm{mV} / \mathrm{s}$ ). Inset: response of the same electrode in fresh $\mathrm{pH} 7$ buffer. B) Variation of peak heights with square root of scan rate (B) and scan rate (C).

Surface characterisation of the adsorbed intermediate highlighted in the inset within Fig. 2A was conducted using high resolution X-ray photoelectron spectroscopy (XPS). Fresh carbon fibre electrode samples were prepared and cyclic voltammetry performed on $100 \mu \mathrm{M}$ CPR under the same conditions as those detailed above. A total of 10 scans were recorded and the electrode then removed and rinsed thoroughly to remove residual / unoxidized CPR. Representative XPS spectra detailing the $\mathrm{S} 2 \mathrm{p}$ and $\mathrm{Cl} 2 \mathrm{p}$ regions are shown in Fig. 3 . While it could be expected that the oxidation 
process would lead to changes in the carbon framework through the incorporation of new $\mathrm{C}-\mathrm{OH}$ bonds, the use of the C 1s XPS profile was not used in this instance as the variety of carbon-oxygen functionality already present in the underlying carbon fibre prevents unambiguous assignment. The unmodified carbon fibre is however devoid of any sulphur or chlorine moieties and hence, it was anticipated that the atomic\% ratio of $\mathrm{S}: \mathrm{Cl}$ at the surface could therefore give some insights into the reactivity of the chlorine substituent. The observed ratio was $0.757 \pm 0.098(N=4)$. Had the chlorine been unreactive towards attack, a ratio of 0.5 would have been expected (Pathway I $\rightarrow$ II $\rightarrow$ III $\leftrightarrow$ IV, Fig. 1) and conversely, the ratio would be expected to be substantially greater than 1 were the chlorine substituent subject to replacement (Pathway I $\rightarrow$ II $\rightarrow \mathbf{V} \leftrightarrow$ VI, Fig. 1). As such, the XPS results indicate that very little of the chlorine is lost (as chloride ion) as a consequence of both the initial oxidation of the CPR and repeated redox cycling of the adsorbed intermediates.

Corroborating evidence for the retention of the chlorine substituent was obtained through examining the electrochemical responses of 2-chloro-1,4-naphthoquinone, 1,4-naphthoquinone and 2-hydroxy-1,4-naphthoquinone as models for the intermediates highlighted in Fig. 1. Repetitive cycling of the chloro-naphthoquinone-hydroquinone system in pH 7 BR buffer did not lead to any significant change in the peak profiles and no transition to the 2-hydroxy analogue was observed, indicating that attack by water does not occur to any appreciable extent. Similarly, a range of NMR experiments $(1 \mathrm{H}, 1 \mathrm{H} 1 \mathrm{H}$ COSY, $13 \mathrm{C}$ and 135 -DEPT) were undertaken to determine if nucleophilic substitution occurs at the 2-chloro-1,4-naphthoquinone in aqueous solution. Detailed spectra for the 2-chloro-naphthoquinone and the 2-hydroxynaphthoquinone are detailed in Fig. S1 along with the investigative protocol followed. In summary, the substitution can be judged by the proton singlet at the 3rd position on both naphthoquinone molecules which occurs at $6.16 \mathrm{ppm}$ for the 2-hydroxy1,4-naphthoquinone and $7.50 \mathrm{ppm}$ on the 2-chloro-1,4-naphthoquinone. It could be anticipated that were nucleophilic substitution to occur at the 2-chloro derivative as a consequence of attack from water, the $6.16 \mathrm{ppm}$ singlet, characteristic of the 2-hydroxy product, would be observed. The emergence of the latter was not observed after 10 mins exposure of the 2-chloro-naphthoquinone to water. 

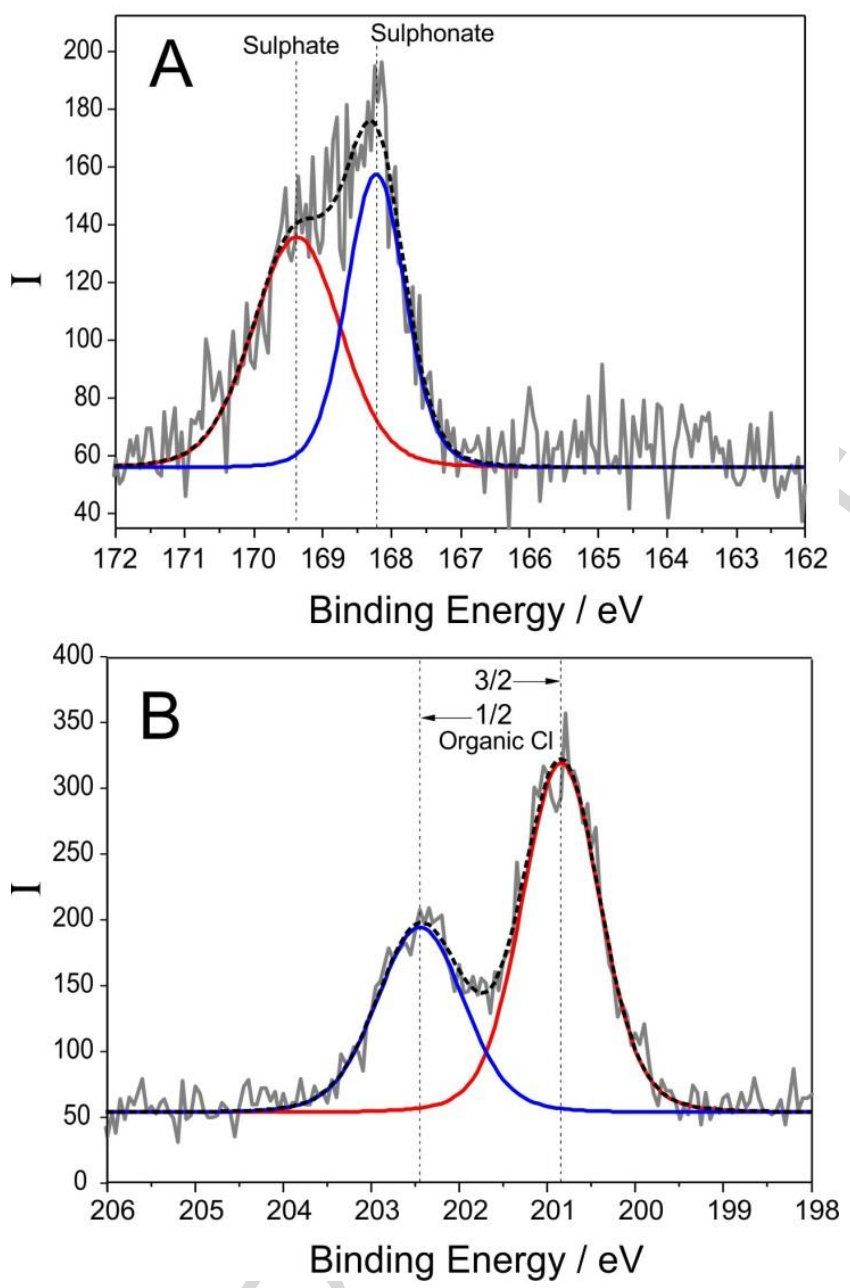

Fig. 3. X-ray photoelectron spectra of the $S 2 p(A)$ and $C l 2 p(B)$ regions of a carbon fibre electrode confirming the presence of adsorbed CPR oxidation products

Evidence supporting the proposition that the intermediate is, in fact, a 1,2-quinone type redox species was acquired through employing a tyrosinase assay with CPR as the enzyme substrate. Tyrosinase is widely used for the quantitative analysis of phenols where it first converts the latter to the 1,2-dihydroxy analogue and then oxidises it to the corresponding 1,2-quinone. The enzyme has been used in a number assays for the detection of coliforms where phenol-galactopyranoside was employed as the bacterial / B-GAL substrate [34]. In the present case, tyrosinase $(23.5 \mathrm{kU} / \mathrm{mL})$ was employed to convert $25 \mu \mathrm{M}$ CPR directly to its 1,2-dihydroxy variant as indicated in Fig. 4A. Square wave voltammetry was used to periodically monitor the reaction in the expectation that the enzymatically produced 1,2-dihydroxy analogue of the CPR molecule would adsorb onto the carbon fibre electrode. The switch to the square wave format was employed to harness the greater discrimination of Faradaic processes from the background thereby improving both detection sensitivity and peak definition. Voltammograms comparing the response of carbon fibre electrodes 
to the enzymatically generated 1,2-quinone and the adsorbed intermediate arising from the electrooxidation of CPR are shown in Fig. 4B.

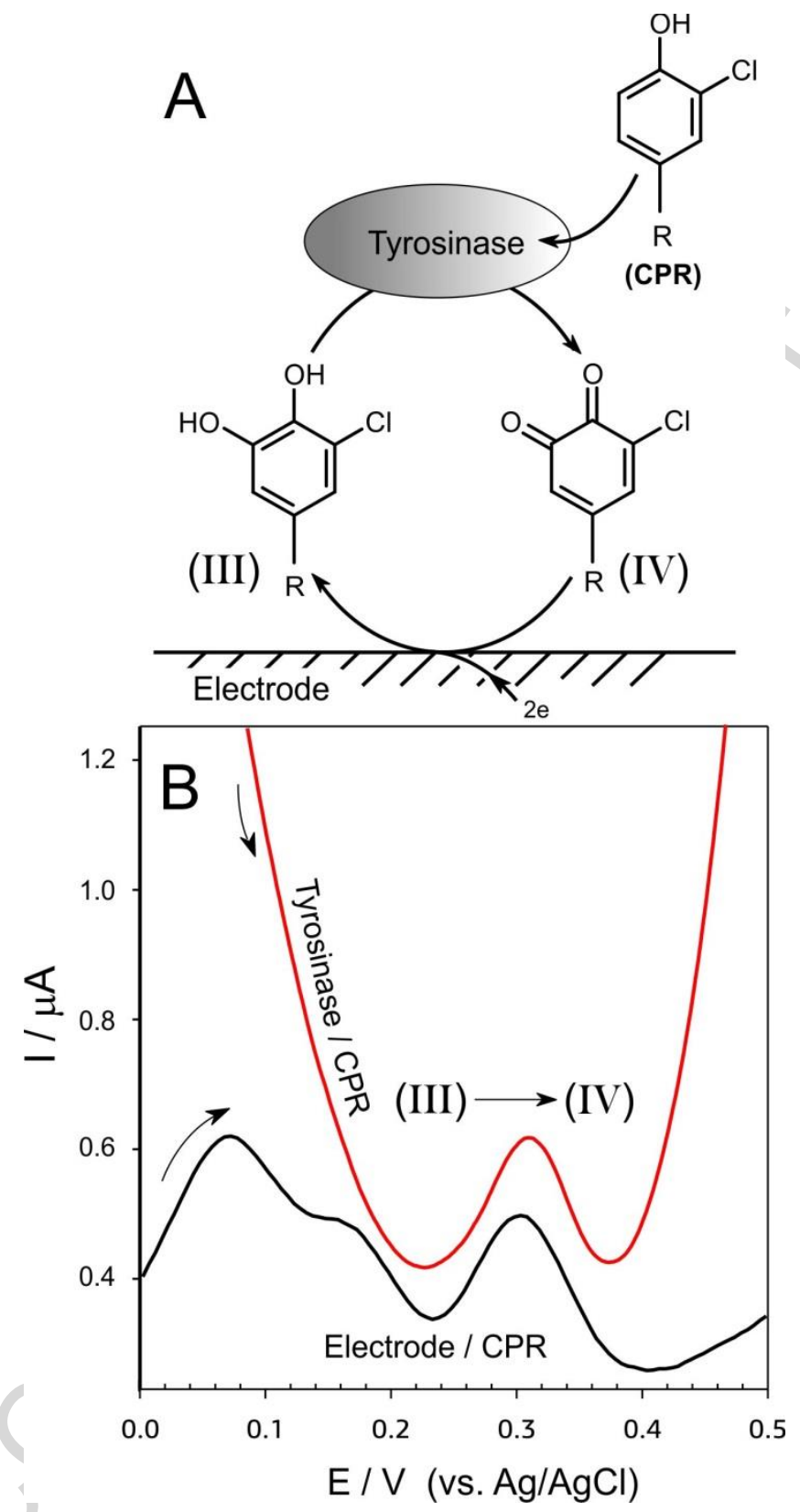

Fig. 4. A) Tyrosinase - CPR reaction scheme and B) Square wave voltammograms comparing the response of a carbon fibre electrode towards the products arising from the electrochemical and enzymatic oxidation of CPR in pH 7 Britton-Robinson buffer.

While the responses indicated in Fig. 4B are not definitive, the close similarity of the peak positions combined with the knowledge of both the enzyme mechanism and the XPS data would suggest that the predominant product in the electro-oxidation of CPR is the 1,2-dihydroxy species in which the chlorine substituent is retained. 


\subsection{Preliminary Bacterial Assays}

The overarching aim was to determine if the adsorbed electrode products arising from the CPR oxidation could themselves be used as a diagnostic handle through which to detect B-GAL activity. The standard coliform assay involves incubating the bacteria in the presence of a labelled galactose substrate. It is commonplace to introduce polymyxin B and lysozyme to enable the release of the B-GAL enzyme into the extracellular assay medium and thereby enhancing the rate at which the labelled substrate is hydrolysed[35]. In the case of chlorophenol red galactopyranoside (CPRG), there is a distinct colorimetric signal upon the B-GAL enzyme cleaving the CPR label with the latter providing a magenta colouration $(\lambda \max 575 \mathrm{~nm})$. Achieving electrochemical distinction between the labelled substrate and the hydrolysed label however is much more difficult as the oxidation potentials of the two can be similar. Inspection of the structure of CPR in Schematic 1 reveals that the galactose is tethered to only one of the two phenolic functional groups. The remaining phenol is therefore capable of being oxidised at the electrode before any interaction with the B-GAL enzyme and could give rise to a false positive. This possibility was confirmed when comparing the square wave voltammograms highlighted in Fig. $\mathbf{5}$.
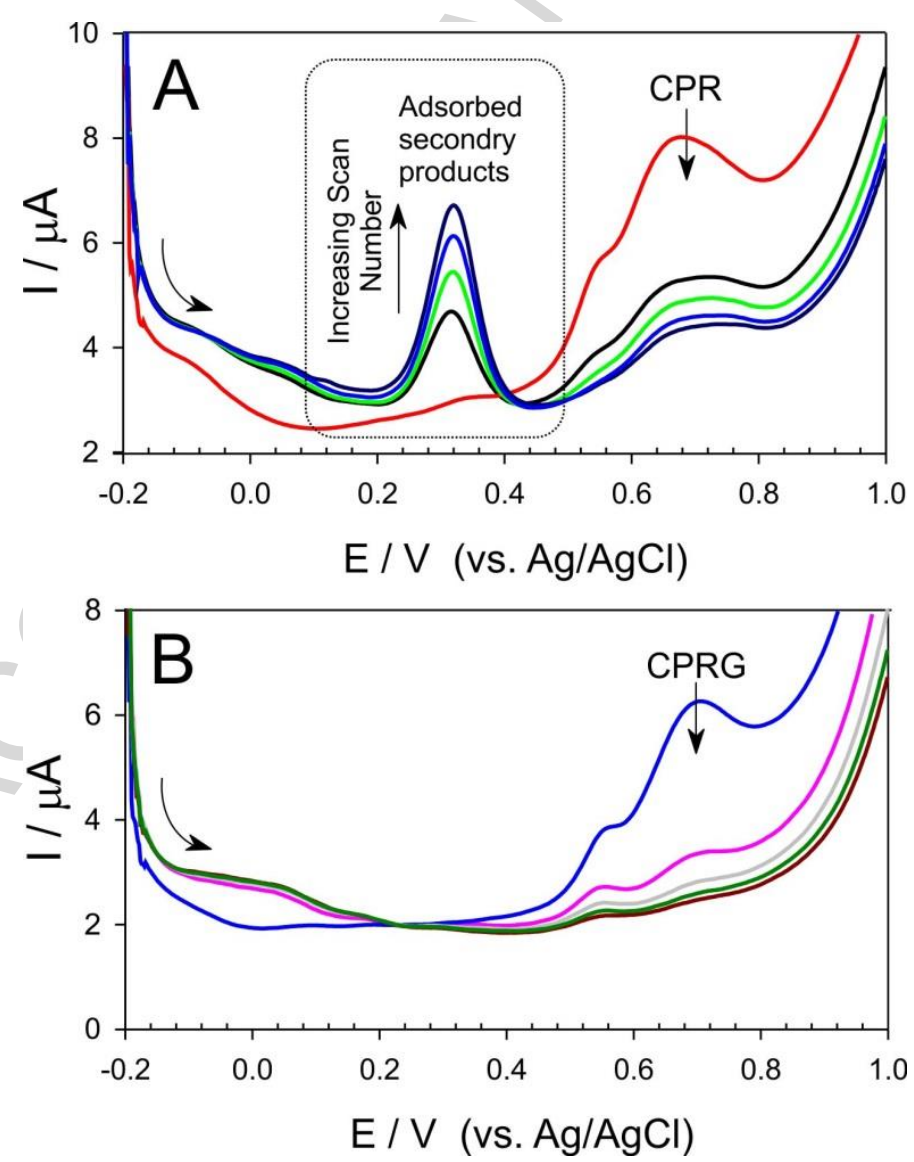

Fig. 5. Square wave voltammograms comparing the consecutive scanning response of carbon fibre electrodes towards (A) $10 \mu \mathrm{M}$ chlorophenol red (CPR) and (B) its galactopyranoside derivative (CPRG) in $\mathrm{pH} 7$ Britton-Robinson buffer. 
Both CPR and CPRG exhibit similar oxidation profiles on the first sweep and would, ordinarily, negate the possibility of exploiting the direct electrochemical oxidation of CPR as a diagnostic for B-GAL activity. The CPRG is normally supplied in excess as the enzyme substrate and thus differentiation between the hydrolysed CPR and its parent is not possible under these conditions. Wutor and colleagues used various metallophthallocyanine modified glassy carbon electrodes to discriminate between the CPR and CPRG, though the mechanism through which the selectivity was achieved is unclear. Examination of Fig. $\mathbf{5}$ however, reveals a possible solution where repetitive scanning of CPR leads to the generation of 1,2-quinone species which adsorb to the electrode. This is consistent with the responses discussed earlier but is of particular significance here when compared to the results obtained with CPRG where no accumulation was observed.

It is possible that upon oxidising CPRG, it too follows the transition pathway I $\rightarrow$ II $\rightarrow$ III highlighted in Fig. 1. It is possible that the oxidation of the free phenolic group in the CPRG molecule gives rise to a 1,2-quinone system not unlike that proposed for the CPR molecule. The absence of any accumulation at the electrode could be attributed to the solubilising effect of the attached galactose substituent - allowing diffusion away from the electrode and hence prevents detection. Thus, while direct oxidation is clearly impractical as a diagnostic marker at simple carbon electrodes in the presence of both CPR and CPRG, the products of the oxidation could offer an alternative approach and enhanced selectivity.

The applicability of the approach was tested through following a conventional galactopyranosidase assay format in which $E$. coli were incubated in combination with isopropyl- $\beta$-dthiogalactopyranoside (IPTG) to increase expression of the $\beta$-GAL enzyme [31,32]. Thereafter, the bacteria were harvested $\left(10^{8} \mathrm{CFU} / \mathrm{mL}\right)$, lysozyme $(1 \mathrm{mg} / \mathrm{mL})$ and $(500 \mu \mathrm{M}) \mathrm{CPRG}$ added and the mixture incubated at $37^{\circ} \mathrm{C}$. Square wave voltammograms were recorded after $2.5 \mathrm{~h}$ and $24 \mathrm{~h}$ and the responses obtained at the carbon fibre electrode are detailed in Fig. 6. After 24 h, repetitive scanning $(-0.2 \mathrm{~V}$ to $+1 \mathrm{~V})$ leads to the gradual accumulation of the adsorbed electrogenerated product. It is noteworthy that there is no peak at $+0.3 \mathrm{~V}$ on the first scan but the 1,2-quinone product emerges on the $2^{\text {nd }}$ and subsequent scans. A critical point to note is that the adsorbed quinone, after 5 scans, presents a peak magnitude that is greater than the CPR / CPRG oxidation process initially observed on scan 1 . The main challenge to coliform detection is the acquisition of a test result in as short a time as possible. Square wave voltammograms detailing the response obtained after $2.5 \mathrm{~h}$ are shown in the Inset within Fig. 6. Again, the accumulation of the electrogenerated quinone can be seen and follows much the same trend as that observed with the $24 \mathrm{~h}$ sample. 


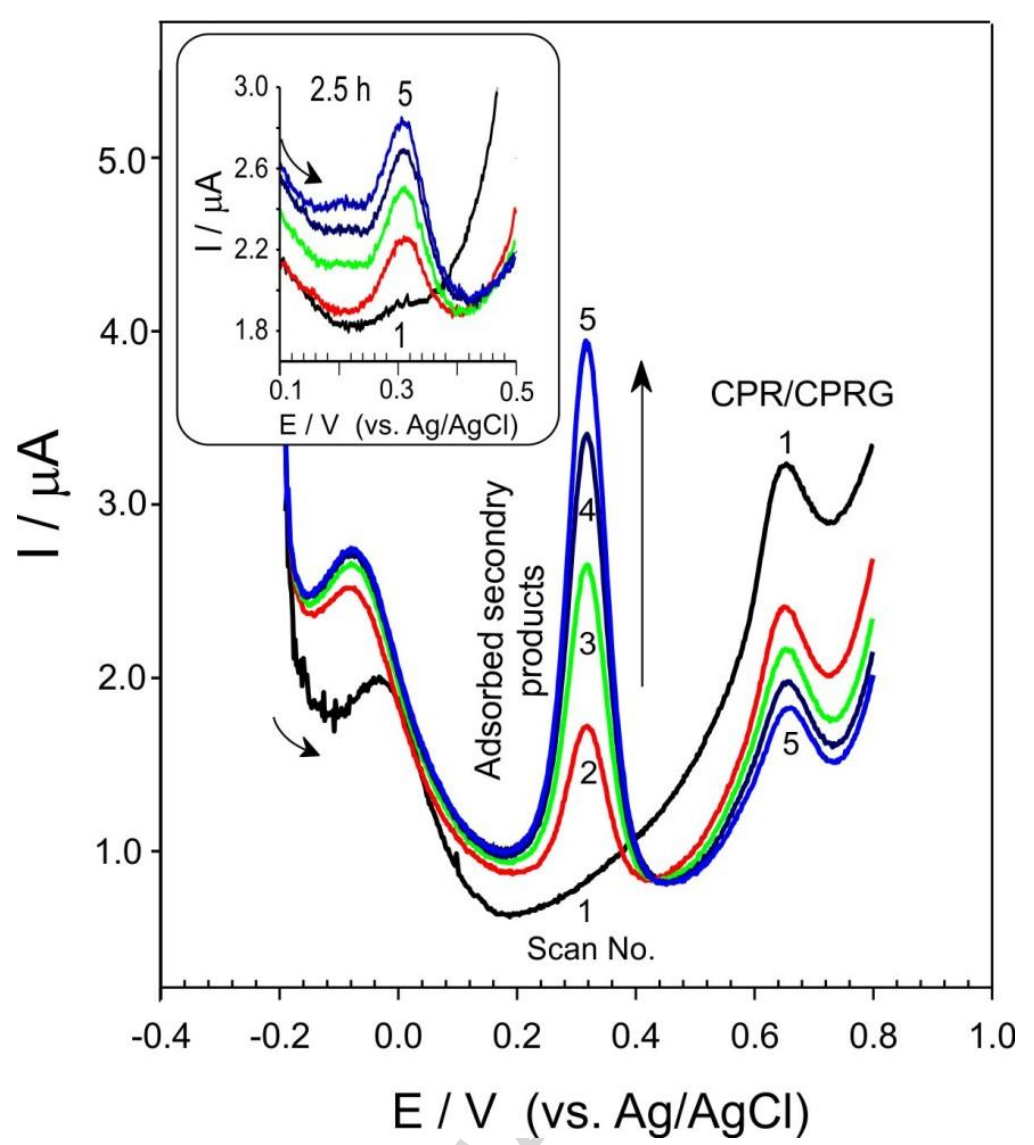

Fig. 6. Square wave voltammograms comparing the consecutive scanning response of carbon fibre electrodes in a lysed E.coli $\left(10^{8} \mathrm{CFU} / \mathrm{mL}\right)$ solution containing $500 \mu \mathrm{M}$ CPRG following incubation for $24 \mathrm{~h}$. Inset: Scans obtained after $2.5 \mathrm{~h}$. Scans conducted in pH 7 Minimal Media buffer.

A large number of electrochemical assays exploiting B-GAL have been developed in recent years and have exploited: p-nitrophenol (PNP) [36], p-aminophenol (PAP), 1-aminonaphthol (AN) [37], 8-hydroxyquinoline[38] and chlorophenol red (CPR) [20]. The use of PAP labelled galactose is the most common approach and can be attributed to the low oxidation potential (typically $+0.1 \mathrm{~V}$ to $+0.3 \mathrm{~V}$ ) required to detect the PAP released [31,39-41]. The detection of the PAP is not however without problems as the low oxidation potential can also create issues over the stability where the presence of oxygen, particularly at prolonged incubation periods, will inevitably lead to the oxidation of both PAP and can result in the degradation of the target marker. In contrast, CPRG is much more stable as indicated by the more positive potential required for its direct oxidation but it is the ability to accumulate the oxidation product that could inform future designs.

The carbon fibre substrate has served as a conductive matrix through which to monitor the various molecular transformations and, being relatively inexpensive, could point the way towards simple disposable electrode systems. Attempting to detect $1 \mathrm{CFU} / 100 \mathrm{~mL}$ however presents a considerable challenge - especially where the emphasis is on short incubation periods. It is 
inevitable that some form of preconcentration will be required, followed by incubation with a labelled galactose substrate. In such scenarios it is still critical to preconcentrate the released label in order to improve detection limits. It could be envisaged that the macro porous nature of the carbon fibre employed here could serve as a conductive filter acting as both generator-collector of the 1,2quinone species. The passage of the initially preconcentrated bacterial solution through the carbon fibre mesh would enable the oxidation of the CPR released by the action of B-GAL to the quinone (generation) which subsequently accumulates at the same fibre (collection). The key advantage here would be that rather than relying on diffusion limited transport of CPR to the electrode and hence a slow accumulation of the product, the imposition of flow through the conductive fibre would enable rapid accumulation of most of the available CPR and greatly improve detection response times and sensitivity. Pursuit of such a system is beyond the scope of the present investigation, but the responses highlighted here effectively demonstrate the proof of principle and highlight an avenue for further exploration.

\subsection{Conclusions}

Chlorophenol red has been used extensively in the development of colorimetric assays but has been largely ignored in electrochemical assays. This could be attributed to the fact that the large positive potentials needed to acquire a signal are unattractive from an analytical perspective where interference from other matrix constituents can be problematic and where the electrode fouling commonly associated with phenol oxidation can compromise reproducibility. The results presented here highlight an innovative approach to the detection of the label where the exploitation of quinone type intermediates offer routes through which enhanced selectivity and sensitivity can be obtained with inexpensive substrates. The electrochemical generation of the 1,2-quinone intermediate and its subsequent accumulation at the surface of the carbon electrode is readily detected at $+0.3 \mathrm{~V}$ which stands in marked contrast to the conventional oxidation potential required for the parent phenol $(+0.7 \mathrm{~V})$. No interference was observed when conducting the assay in bacterial culture containing E.coli with a clear, unambiguous oxidation peak process. A critical advantage is that the accumulation of the quinone reaction product with successive scanning offers a means of amplifying the signal which could significantly reduce the time required for incubation. 


\subsection{Acknowledgements}

We wish to thank the Global Challenges Research Fund (GCRF) UK Research and Innovation (SAFEWATER: EPSRC Grant Reference EP/P032427/1), the Department for the Economy Northern Ireland (DfE), the British Council (DST-UKIERI: Ref 65/2017), the University of Central Lancashire and Kimal PLC for supporting this work. 


\section{References}

1. S. Moussa, Review-Microelectrodes: An Overview of Probe Development and Bioelectrochemistry Applications from 2013 to 2018, Journal of The Electrochemical Society Volume: 166 (2019) 19457111

2. F.Q. Li, Z.G. Yu, X.D. Han, R.Y. Lai, Electrochemical aptamer-based sensors for food and water analysis: A review, Anal. Chim. Acta., 1051 (2019) 1-23

3. N. Baig, M. Sajid, T.A. Saleh, Recent trends in nanomaterial-modified electrodes for electroanalytical applications, TRAC Trends in Anal. Chem., 111 (2019) 47-61

4. A.T.E. Vilian, B. Dinesh, S.M. Kang, U.M. Krishnan, Y.S.Huh, Y.K. Han, Recent advances in molybdenum disulfide-based electrode materials for electroanalytical applications, Microchimica Acta 186 (2019) DOI: 10.1007/s00604-019-3287-y

5. A.K. Srivastava, S.S. Upadhyay, C.R. Rawool, N.S. Punde, A.S. Rajpurohit, Voltammetric Techniques for the Analysis of Drugs using Nanomaterials based Chemically Modified Electrodes, Curr. Anal. Chem., 15 (2019) 249-276

6. K. Ngamchuea, K. Chaisiwamongkhol, C. Batchelor-McAuley, R.G. Compton, Chemical analysis in saliva and the search for salivary biomarkers - a tutorial review, Analyst, 143 (2018) 81-99

7. N. Kumar, Y. Hu, S. Singh S, et al. Emerging biosensor platforms for the assessment of water-borne pathogens. Analyst 143 (2018) 359-373. DOI: 10.1039/c7an00983f.

8. S. Kuss, H.M.A. Amin and R.G. Compton, Electrochemical Detection of Pathogenic Bacteria-Recent Strategies, Advances and Challenges. Chemistry - An Asian Journal. (2018) DOI: 10.1002/asia.201800798.

9. J. Monzó, I. Insua, F. Fernandez-Trillo, et al. Fundamentals, achievements and challenges in the electrochemical sensing of pathogens. Analyst 140 (2015) 7116-7128. DOI: 10.1039/c5an01330e.

10. M.A. Syed, Advances in nanodiagnostic techniques for microbial agents. Biosensors and Bioelectronics 51 (2014) 391-400. DOI: 10.1016/j.bios.2013.08.010.

11. A. Pardee, F. Jacob, J. Monod, The genetic control and cytoplasmic expression of "Inducibility" in the synthesis of $\beta$-galactosidase by E. coli, J. Mol. Biol. 1 (1959) 165-178. doi:10.1016/S00222836(59)80045-0.

12. J. -P Tenu, O.M. Viratelle, J. Garnier, J. Yon, $\mathrm{pH}$ Dependence of the Activity of $\beta$-Galactosidase from Escherichia coli, Eur. J. Biochem. 20 (1971) 363-370. doi:10.1111/j.1432-1033.1971.tb01402.x.

13. C. Jendresen, M.R. Daws, L.N.G. Nilsson, An improved CPRG colorimetric ligand-receptor signal transduction assay based on beta-galactosidase activity in mammalian BWZ-reporter cells, J. Pharmacol. Toxicol. Methods. 90 (2018) 67-75. doi:10.1016/j.vascn.2017.11.004.

14. N.J. Ashbolt, W.O.K. Grabow, M. Snozzi, WHO Guidelines for Drinking-Water Quality: Indicators of microbial water quality, IWA Publ. London, UK. (2001).

15. K. Amini, H.B. Kraatz, Recent advances and developments in monitoring biological agents in water samples, Rev. Environ. Sci. Biotechnol. 14 (2014) 23-48. doi:10.1007/s11157-014-9351-5. 
16. F.S. Alhamlan, A.A. Al-Qahtani, M.N. Al-Ahdal, Recommended advanced techniques for waterborne pathogen detection in developing countries, J. Infect. Dev. Ctries. 9 (2015) 128-135. doi:10.3855/jidc.6101.

17. G. Saxena, R.N. Bharagava, G. Kaithwas, A. Raj, Microbial indicators, pathogens and methods for their monitoring in water environment, J. Water Health. 13 (2015) 319-339. doi:10.2166/wh.2014.275.

18. T. Bigham, C. Casimero, J.S.G. Dooley, N.G. Ternan, W.J. Snelling, J. Davis, Microbial water quality: Voltammetric detection of coliforms based on riboflavin-ferrocyanide redox couples, Electrochem. Commun. 101 (2019) 99-103. doi:10.1016/j.elecom.2019.02.022.

19. R. Bain, J. Bartram, M. Elliott, R. Matthews, L. Mcmahan, R. Tung, P. Chuang, S. Gundry, A summary catalogue of microbial drinking water tests for low and medium resource settings, Int. J. Environ. Res. Public Health. 9 (2012) 1609-1625. doi:10.3390/ijerph9051609.

20. V.C. Wutor, C.A. Togo, J.L. Limson, B.I. Pletschke, A novel biosensor for the detection and monitoring of $\beta$-d-galactosidase of faecal origin in water, Enzyme Microb. Technol. (2007). doi:10.1016/j.enzmictec.2006.10.039.

21. United Nations, EXECUTIVE SUMMARY Sustainable Development Goal 6 Synthesis Report 2018 on Water and Sanitation, 2018. doi:10.1002/net.20371.

22. C. Berrı, F. Ferna, E. Garrido-ramı, C. Gutie, on glassy carbon electrodes modified with graphite zeolite mixtures, (2014) 1295-1306. doi:10.1007/s10800-014-0763-2.

23. A. Kawde, M.A. Morsy, N. Odewunmi, From Electrode Surface Fouling to Sensitive Electroanalytical Determination of Phenols, (2013) 1547-1555. doi:10.1002/elan.201300101.

24. S. Biniak, M. Pakuła, Electro-oxidation of chlorophenols on powdered carbon electrodes of different porosity, (2015) 369-383. doi:10.1007/s11144-014-0797-9.

25. Y. Zhang, Q. Cheng, M. Zheng, X. Liu, K. Wu, Iron oxyhydroxide nanorods with high electrochemical reactivity as a sensitive and rapid determination platform for 4-chlorophenol, J. Hazard. Mater. 307 (2016) 36-42. doi:10.1016/j.jhazmat.2015.12.064.

26. H. Liu, Z. Zhang, M. Ren, J. Guan, N. Lu, J. Qu, X. Yuan, Preparation of the CNTs / AG / ITO electrode with high electro-catalytic activity for 2-chlorophenol degradation and the potential risks from intermediates, J. Hazard. Mater. 359 (2018) 148-156. doi:10.1016/j.jhazmat.2018.07.046.

27. M. Ferreira, H. Varela, R. M. Torresi, G.Tremiliosi-Filho, Electrode passivation caused by polymerization of different phenolic compounds, Electrochimica Acta 52 (2006) 434-442

28. J.S.N. Dutt, C. Livingstone, M.F. Cardosi, S.J. Wilkins, J. Davis, A clinical assessment of direct electrochemical urate measurements, Talanta. 68 (2006). doi:10.1016/j.talanta.2005.08.020.

29. A. Anderson, J. Phair, J. Benson, B. Meenan, J. Davis, Investigating the use of endogenous quinoid moieties on carbon fibre as means of developing micro pH sensors, Mater. Sci. Eng. C. 43 (2014) 533537. doi:10.1016/j.msec.2014.07.038.

30. S. Neufeind, N. Hulsken, J. Neudorfl, N. Schlorer, H. Schmalz, SchmalzTotal synthesis of cyclomumbaistatin analogues through anionic homo-fries rearrangement, Chem. Eur J. 17 (2011) 26332641. 
31. A.S. Mittelmann, E.Z. Ron, J. Rishpon, Amperometric quantification of total coliforms and specific detection of Escherichia coli, Anal. Chem. (2002). doi:10.1021/ac0156215.

32. T. Neufeld, A. Schwartz-Mittelmann, D. Biran, E.Z. Ron, J. Rishpon, Combined phage typing and amperometric detection of released enzymatic activity for the specific identification and quantification of bacteria, Anal. Chem. 75 (2003) 580-585. doi:10.1021/ac026083e.

33. C. Briciu-Burghina, B. Heery, F. Regan, Protocol for the recovery and detection of Escherichia coli in environmental water samples, Anal. Chim. Acta. 964 (2017) 178-186. doi:10.1016/j.aca.2017.02.035.

34. B. Serra, M. Dolores Morales, J. Zhang, A.J. Reviejo, E.H. Hall, J.M. Pingarron, In-a-day electrochemical detection of coliforms in drinking water using a tyrosinase composite biosensor, Anal. Chem. 77 (2005) 8115-8121. doi:10.1021/ac051327r.

35. Y. Cheng, Y. Liu, J. Huang, Y. Xian, W. Zhang, Z. Zhang, L. Jin, Rapid amperometric detection of coliforms based on MWNTs/Nafion composite film modified glass carbon electrode, Talanta. (2008). doi:10.1016/j.talanta.2007.10.047.

36. F. Tanvir, A. Yaqub, S. Tanvir, W.A. Anderson, Colorimetric enumeration of bacterial contamination in water based on $\beta$-galactosidase gold nanoshell activity, Enzyme Microb. Technol. 99 (2017) 49-56. doi:10.1016/j.enzmictec.2017.01.006.

37. S. Noh, Y. Choe, V. Tamilavan, M.H. Hyun, H.Y. Kang, H. Yang, Facile electrochemical detection of Escherichia coli using redox cycling of the product generated by the intracellular $\beta$-d-galactosidase, Sensors Actuators, B Chem. (2015). doi:10.1016/j.snb.2014.12.073.

38. J. Ettenauer, K. Zuser, K. Kellner, T. Posnicek, M. Brandl, 8-hydroxyquinoline-glucuronide Sodium Salt Used as Electroactive Substrate for a Sensitive Voltammetric Detection of Escherichia coli in Water Samples, Procedia Eng. 168 (2016) 143-146. doi:10.1016/j.proeng.2016.11.179.

39. P. Geng, J. Zheng, X. Zhang, Q. Wang, W. Zhang, L. Jin, Z. Feng, Z. Wu, Rapid detection of Escherichia coli by flow injection analysis coupled with amperometric method using an IrO2-Pd chemically modified electrode, Electrochem. Commun. (2007). doi:10.1016/j.elecom.2007.05.023.

40. Q. Yang, Y. Liang, T. Zhou, G. Shi, L. Jin, Electrochemical investigation of platinum-coated gold nanoporous film and its application for Escherichia coli rapid measurement, Electrochem. Commun. 11 (2009) 893-896. doi:10.1016/j.elecom.2009.02.021.

41. O. Laczka, C. García-Aljaro, F.J. del Campo, F.X.M. Pascual, J. Mas-Gordi, E. Baldrich, Amperometric detection of Enterobacteriaceae in river water by measuring $\beta$-galactosidase activity at interdigitated microelectrode arrays, Anal. Chim. Acta. 677 (2010) 156-161. doi:10.1016/j.aca.2010.08.001. 


\section{Graphical Abstract}

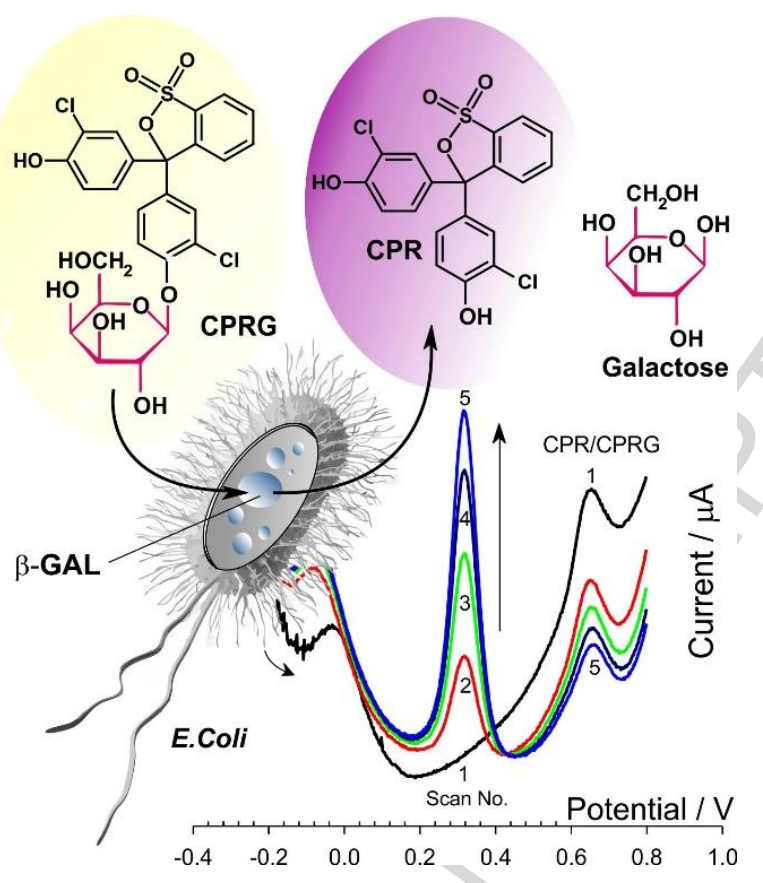




\section{Highlights}

- Electrochemical characterisation of chlorophenol red and galactopyranoside analogue

- Elucidation of oxidative mechanisms and identification of intermediates

- Development of an analytical pathway via accumulation of adsorbed redox products

- Demonstration of rapid E.coli detection through exploitation of adsorbed products 